\title{
Pengaruh Penggunaan Multimedia Terhadap Minat Belajar IPS Siswa SMK
}

\author{
Husnul Khatimah \\ Program studi Pendidikan Sejarah, STKIP Yapis Dompu \\ E-mail corresponding: khatimahhusnul@gmail.com
}

\begin{abstract}
Article History: Received: 2021-07-22 || Revised: 2021-07-28 || Published: 2021-08-27
Sejarah Artikel : Diterima: 2021-07-22 || Direvisi: 2021-07-28 || Dipublikasi: 2021-08-27
\end{abstract}

\begin{abstract}
The type of research used in this study is quantitative research with a quantitative approach, with the population in this study being all class X students of SMK Negeri 2 Dompu in the 2016/2017 academic year, totaling 197 students consisting of 6 classes, because the population is the entire class X students. SMK Negeri 2 Dompu for the 2016/2017 academic year, which totaled 197 students, and the sample in class X TAV1 of SMK Negeri 2 Dompu was 33 students. sampling (porposive sampling), and data analysis using: simple linear regression analysis, correlation coefficient analysis, determination coefficient analysis, and research hypothesis testing ( $\mathrm{T}$ test), with the results of the study showing that tcount 0.996 is smaller than ttable 1.684 $(0.996<1,684)$ at degrees of freedom (dk) of 33 with a significance level of $5 \%$, meaning that the hypothesis (Ha) is rejected and the hypothesis (Ho) is accepted. Studying Social Studies at SMK Negeri 2 Dompu in the 2016/2017 academic year".
\end{abstract}

Keywords: Multimedia, Interest in Learning, Social Studies, Students

\begin{abstract}
Abstrak
Jenis penelitian yang digunakan dalam penelitian ini adalah penelitian kuantitatif dengan pendekatan kuantitatif, dengan populasi dalam penelitian ini adalah seluruh siswa kelas X SMK Negeri 2 Dompu tahun pembelajaran 2016/2017 yang berjumlah 197 siswa yang terdiri dari 6 kelas, karena populasi adalah keseluruhan siswa kelas X SMK Negeri 2 Dompu Tahun Pembelajaran 2016/2017 yang berjumlah 197 orang siswa, dan sample pada kelas X TAV1 SMK Negeri 2 Dompu yang berjumlah 33 orang siswa. pengambilan sampel secara (porposive sampling), dan analisis data menggunakan: Analisis Regresi Linear sederhana, Analisis koofesien korelasi, Analisis koofesien Determinasi, dan Pengujian hipotesis penelitian ( uji T), dengan hasil penelitian menunjukan bahwa $t_{\text {hitung }} 0,996$ lebih kecil dari $t_{\text {tabel }} 1,684(0,996<1,684)$ pada derajat kebebasan (dk) dari 33dengan taraf nyata $5 \%$, berarti hipotesis $\left(\mathrm{H}_{\mathrm{a}}\right)$ ditolak dan hipotesis $\left(\mathrm{H}_{\mathrm{o}}\right)$ diterima, Berdasarkan uraian di atas maka hipotesis yang diajukan dalam penelitian ini DITOLAK artinya tidak ada Pengaruh "Pengaruh Penggunaan Multimedia Terhadap Minat Belajar IPS SMK Negeri 2 Dompu tahun pembelajaran 2016/2017".
\end{abstract}

Kata kunci: Multimedia, Minat Belajar, IPS, Siswa

\section{PENDAHULUAN}

Pendidikan merupakan penyiapan Sumber Daya Manusia (SDM) untuk pembangunan dan kesejahteraan hidup di masa depan, upaya tersebut hendaknya bermuara pada kemajuan IPTEK yang sejalan dengan tuntunan dan kebutuhan masyarakat, oleh karena itu mutlak diperlukan upaya-upaya peningkatan kualitas pendidikan Indonesia pada semua jenjang dimulai dari pendidikan. Semakin sadarnya orang akan teknologi yang dapat membantu pembelajaran sudah dapat dirasakan, Kemajuan ilmu pengetahuan dan teknologi, khususnya teknologi informasi, sangat berpengaruh terhadap penyusunan implementasi strategi pembelajaran.Melalui kemajuan tersebut para guru dapat menggunakan berbagai media sesuai dengan kebutuhan dan tujuan pembelajaran. Dengan menggunakan media komunikasi bukan saja dapat mempermudah dan mengefektifkan proses pembelajaran, akan tetapi juga bisa membuat proses pembelajaran lebih menarik (Sanjaya, 2006: 29), Multimedia terdiri dari : LCD (proyektor/layar). Adapun fungsi media yaitu yang terdiri dari : (1) Fungsi utama teknologi yaitu sebagai alat bantu mengajar, (2) Dengan maksudnya audiovisual instruction, teknologi berfungsi memberikan pengalaman kongkret kepada siswa, (3) Munculnya teori komunikasi menyebabkan teknologi mempunyai fungsi sebagai alat penyalur 
pesan/Informasi belajar, (4) Adapun penggunaan pendekatan sistem dalam pembelajaran dan (5) AkhirnyaTeknologi bukan saja sekedar berfungsi sebagai peraga bagi guru, tetapi pembawa informasi/pesan pembelajaran yang dibutuhkan siswa.

Selain dari fungsinya multimedia juga mempunyai kegunaan dalam pembelajaran yaitu terdiri dari : (1) Memperjelas penyajian pesan agar tidak terlalu bersifat verbalistis, (2) Mengatasi keterbatasan ruang, waktu dan daya indera, (3) Dengan menggunakan pembelajaran secara tepat dan bervariasi dapat diatasi sikap pasif pada siswa dan (4) Dengan sifat yang unik pada setiap siswa, ditambah lagi dengan lingkungan dan pengalaman yang berbeda. Sedangkan kurikulum dan materi pembelajaran ditentukan sama untuk siswa, maka guru akan banyak mengalami kesulitan bilamana semuanya itu harus diatasi sendiri jadi masalah ini dapat diatasi dengan tehnologi (Soeharto, dkk, 2003: 34), Untuk mencapai tujuan pembelajaran IPS khususnya pada Kompetensi Dasar (KD) Perkembangan seni aksara dan seni sastra pada zaman Islam, sebagaimana disebutkan diatas maka penataan program pengajaran didalam kurikulum guna mendukung terlaksananya pembelajaranmaka pelajaran IPS dikelas belum cukup.

Hal lain yang masih harus dipenuhi adalah melengkapinya dengan berbagai pedoman yang dapat dipacu dalam mengimplementasikan pembelajaran IPS yang efektif dikelas, misalnya perbaikan tehnik penyajian dalam kegiatan pembelajaran berlangsung, Berdasarkan pada hasil wawancara yang dilakukan pada tanggal 3 febuari 2017 yang dilakukan peneliti dengan guru mata pelajaran IPS yaitu Bapak Lubis, S. Pd. mengatakan bahwa dalam proses pembelajaran berlangsung dengan menggunakan media multimedia, lebih banyak siswa yang menarik dan rajin karena dengan menggunakan media tersebut siswa lebih aktif karena memang mereka bisa melihat lebih jelas,tentangPerkembangan seni aksara dan seni sastra pada zaman Islam, Berdasarkan uraian latarbelakang diatas maka penulis tertarik untuk meneliti tentang Pengaruh Penggunaan Multimedia Terhadap Minat Belajar IPS Siswa SMK Negeri 2 Dompu Tahun Pembelajaran 2016/2017.

\section{METODE PENELITIAN}

Jenis penelitian yang digunakan dalam penelitian ini adalah penelitian kuantitatif dengan pendekatan kuantitatif, dalam penelitian kuantitatif menurut Nana Sudjana dan Ibrahim (2001: 195), diupayakan analisis isi menggunakan ukuran frekuensi simbol atau atribut, atau menggunakan bilangan (numerik) agar mengadung makna yang lebih tepat daripada menggunakan kata-kata: lebih, kurang, lebih kurang, bertambah kurang dan lain-lain.Penelitian kuantitatif adalah penelitian yang difokuskan pada kajian fenomena objektif untuk dikaji secara kuantitatif, Jenis datanya dikuantifikasikan dalam bentuk angka dan dianalisis menggunakan statistik. Penelitian kuantitatif didasari filsafat positivisme, aliran filsafat yang fokus kajian pada fenomena objektif (Musfiqon, 2012: 59), adapun populasi dalam penelitian ini adalah seluruh siswa kelas X SMK Negeri 2 Dompu tahun pembelajaran 2016/2017 yang berjumlah 197 siswa yang terdiri dari 6 kelas, karena populasi adalah keseluruhan siswa kelas X SMK Negeri 2 Dompu Tahun Pembelajaran 2016/2017 yang berjumlah 197 orang siswa, maka sampel dalam penelitian ini adalah kelas X TAV1 yang berjumlah 33 orang siswa. pengambilan sampel secara (porposive sampling), Untuk mencapai hasil dengan tujuan penelitian sangatlah tergantung dari lengkap tidaknya data yang diperoleh.Oleh karenaitu ,teknik pengumpulan data tidak diabaikan begitu saja, diantaranya: Angket, dan Dokumentasi.

Teknik analisis data yang digunakan sudah jelas, diarahkan untuk menjawab rumsan masalah atau menguji hipotesis yang telah dirumuskan dalam proposal, karena datanya kuantitatif, maka teknik analisis data menggunakan metode statistik yang sudah tersedia (Sugiyono, 2012: 243), Berdasarkan data yang diambil hasil dari hasil minat belar siswa, maka akan dilakukan analisis untuk menguji kebenaran hipotesis untuk menganalisis data tentang Pengaruh Penggunaan Multimedia (variabel x) Terhadap Minat Belajar Siswa (variabel Y) maka data tersebut dapat dianalisi dengan menggunakan rumus analisis regresi linear sederhana dengan menggunakan uji T.

1) Analisis Regresi Linear sederhana

Regresi Linear sederhana adalah metote statistik yang berfungsi untuk menguji hubunan sebab akibat antara variael bebas $(\mathrm{X})$ dengan variael terikat( $\mathrm{Y})$.

Persamaan analisis regresi linear yang digunakan.

$\mathbf{Y}=\mathbf{a}+\mathbf{b X}$ 
Keterangan :

$\mathrm{Y}=$ variabel terikat (minat belajar siswa)

$\mathrm{X}=$ variabel bebas (penggunaan multimedia)

$\mathrm{a}=$ konstanta

$\mathrm{b}=$ nilai koofesien

Untuk menghitung nilai a (nilai konstanta) digunakan rumus sebagai berikut $\mathrm{a}=\left(\sum \mathrm{y}\right)\left(\sum \mathrm{x}^{2}\right)-\left(\sum \mathrm{x}\right)\left(\sum \mathrm{xy}\right)$ $\mathrm{n} \sum \mathrm{x}^{2}-\left(\sum \mathrm{x}\right)^{2}$

untuk mencari nilai b ( nilai koofesien) digunakan rumus sebagai berikut $\mathrm{b}=\frac{\mathrm{n} \sum \mathrm{xy}-\left(\sum \mathrm{x}\right)\left(\sum \mathrm{y}\right)}{\mathrm{n} \sum \mathrm{x}^{2}-\left(\sum \mathrm{x}\right)^{2}} \quad$ (sugiyono, 2004: 243) $\mathrm{n} \sum \mathrm{x}^{2}-\left(\sum \mathrm{x}\right)^{2}$

2) Analisis koofesien korelasi

Setelah menghing nilai a (konstata) dan nilai b (koofesien)selanjutnya menghitung analisis koofesien korelasi, dengan Rumus:

$$
r x y=\sqrt{\left\{\left(n \sum x 2-\left(\sum x\right) 2\right\}-\left\{\left(\mathrm{n} \sum \mathrm{y} 2-\left(\sum y\right) 2\right\}\right.\right.}
$$

3) Analisis koofesien Determinasi

Setelah menghitung nilai koofesien korelkasi, dilanjutkan dengan menghitung analisis koofesien determinasi dengan rumus

$$
\mathrm{D}=\mathrm{r}^{2} \mathrm{X} 100 \%
$$

4) Pengujian hipotesis penelitian (uji T)

Untuk membuktikan hipotesis $(\mathrm{Ha}$ ) yang berbunyi terdapat pengaruh yang positif dan signifikan antara penggunaan multimedia terhadap minat belajar siswa di SMK Negeri 2 dompu maka digunakan rumus berikut

$$
t=\frac{r \sqrt{n-2}}{\sqrt{1-r^{2}}}
$$

Kriteria penerimaan hipotesis adalah apabila hipotesis nol (Ho) diterima dan hipotesis alternatif (Ha) ditolak sebaliknya apabila penolakan terhdap hipotesis nol $(\mathrm{Ha})$ dan penerimaan terhadap hipotesis alternatif $(\mathrm{Ha})$

\section{HASIL DAN PEMBAHASAN}

\section{A. Hasil Penelitian}

Berikut disajikan tentang keadaan siswa SMK NEGERI 2 DOMPU yang menjadi sasaran penelitian, seperti yang telah diungkapkan pada bab III, bahwa jumlah siswa sebagai sampel penelitian sebanyak 33 orang siswa yang terdiri dari satu kelas yaitu kelas X TAV1. Penelitian ini dilakukan mulai tanggal 08 hingga 10 mei 2017. Penggunaan multimedia dilakukan pada kelas X TAV1. Sesuai jadwal, pembelajaran IPS berlangsung pada hari jum'at jam pelajaran 5-6 (10.45-11.15 WITA).

\section{a) Uji hipotesis}

Untuk mengetahui hasil penelitian ini, maka data yang telah dihimpun selanjutnya akan dianalisis dengan menggunakan rumus regresi linear sederhana. Untuk memudahkan melakukan perhitungan analisis data perlu dibuat sebuah tabel kerja sebagai berikut:

Tabel 1. Distribusi Hasil Penelitian multimedia (X) dengan minat Belajar (Y)

\begin{tabular}{cccccc}
\hline $\mathbf{N O}$ & $\mathbf{X}$ & $\mathbf{Y}$ & $\mathbf{X}^{\mathbf{2}}$ & $\mathbf{Y}^{\mathbf{2}}$ & $\mathbf{X Y}$ \\
\hline 1 & 73 & 69 & 5329 & 4761 & 5037 \\
\hline 2 & 79 & 78 & 6241 & 6084 & 6162 \\
\hline 3 & 82 & 77 & 6724 & 5929 & 6314 \\
\hline 4 & 88 & 88 & 7744 & 7744 & 7744 \\
\hline 5 & 93 & 100 & 8649 & 10000 & 9300 \\
\hline
\end{tabular}




\begin{tabular}{rrrrrr}
\hline 6 & 80 & 80 & 6400 & 6400 & 6400 \\
\hline 7 & 78 & 88 & 6084 & 7744 & 6864 \\
\hline 8 & 76 & 72 & 5776 & 5184 & 5472 \\
\hline 9 & 91 & 100 & 8281 & 10000 & 9100 \\
\hline 10 & 88 & 92 & 7744 & 8464 & 8096 \\
\hline 11 & 87 & 91 & 7569 & 8281 & 7917 \\
\hline 12 & 76 & 75 & 5776 & 5625 & 5700 \\
\hline 13 & 83 & 79 & 6889 & 6241 & 6557 \\
\hline 14 & 88 & 88 & 7744 & 7744 & 7744 \\
\hline 15 & 78 & 84 & 6084 & 7056 & 6552 \\
\hline 16 & 78 & 85 & 6084 & 7225 & 6630 \\
\hline 17 & 80 & 78 & 6400 & 6084 & 6240 \\
\hline 18 & 77 & 86 & 5929 & 7396 & 6622 \\
\hline 19 & 79 & 89 & 6241 & 7921 & 7031 \\
\hline 20 & 76 & 81 & 5776 & 6561 & 6156 \\
\hline 21 & 88 & 69 & 7744 & 4761 & 6072 \\
\hline 22 & 99 & 85 & 9801 & 7225 & 8415 \\
\hline 23 & 83 & 83 & 6889 & 6889 & 6889 \\
\hline 24 & 92 & 95 & 8464 & 9025 & 8740 \\
\hline 25 & 81 & 90 & 6561 & 8100 & 7290 \\
\hline 26 & 90 & 88 & 8100 & 7744 & 7920 \\
\hline 27 & 89 & 89 & 7921 & 7921 & 7921 \\
\hline 28 & 86 & 95 & 7396 & 9025 & 8170 \\
\hline 29 & 89 & 88 & 7921 & 7744 & 7832 \\
\hline 30 & 85 & 86 & 7225 & 7396 & 7310 \\
\hline 31 & 83 & 91 & 6889 & 8281 & 7553 \\
\hline 32 & 83 & 79 & 6889 & 6241 & 6557 \\
\hline 33 & 88 & 91 & 7744 & 8281 & 8008 \\
\hline & 2766 & $\mathbf{2 8 0 9}$ & 233008 & 241077 & 236315 \\
\hline & & & & &
\end{tabular}

Data pada tabulasi diatas merupakan data hasil distribusi dari kedua variabel penelitian. Pendistribusian data penelitian tersebut dimaksudkan untuk mempermudah proses analisis data, dari tabel kerja di atas diperoleh nilai-nilai sebagai berikut:
$\mathrm{N} \quad: 33$
$\sum X \quad: 2766$
$\sum Y \quad: 2809$
$\sum \mathrm{X}^{2} \quad: \mathbf{2 3 3 0 0 8}$
$\sum Y^{2}: 241077$
$\sum X . Y: 236315$

Data pada tabel tersebut di atas, selanjutnya akan di analisis dengan menggunakan rumus regresi linier.

\section{b) Analisis Regresi Linier sederhana}

Regresi linear sederhana adalah metode statistik yang berfungsi untuk menguji hubungan sebab akibat antara variabel bebas $(\mathrm{x})$ terhadap variabel terikat $(\mathrm{y})$ dengan menggunakan rumus sebagai berikut:

$$
\begin{gathered}
a=\frac{\left(\sum y_{i}\right)\left(\sum x_{i}^{2}\right)-\left(\sum x_{i}\right)\left(\sum x_{i} \cdot y_{i}\right)}{n \cdot \sum x_{i}^{2}-\left(x_{i}\right)^{2}} \\
\alpha=\frac{(2,809)(233008)-(2,766) \cdot(236315)}{33(233008)-(2,766)^{2}} \\
a=\frac{(654,519,472)-(653,647,290)}{(7689264)-(7650756)}
\end{gathered}
$$


$a=\underline{872,182}$

38,508

$a=22,649$

Untuk mencari nilai b ( nilai koofesien) digunakan rumus sebagai berikut

$b=\underline{\mathrm{n} \sum \mathrm{xy}}-\left(\sum \mathrm{x}\right)\left(\sum \mathrm{y}\right)$

$\mathrm{n} \sum \mathrm{x}^{2}-\left(\sum \mathrm{x}\right)^{2}$

$b=\underline{33.236315-(2766) \cdot(2809)}$

$33(233008)-(2766)^{2}$

$b=(7,798,395)-(7,769,694)$

$(7,689,264)-(7,650,756)$

$$
b=\frac{28,701}{38,502}
$$

$b=0,745$

Persamaan analisis regresi linear yang digunakan rumus sebagai berikut:

$\mathrm{Y}=\mathrm{a}+\mathrm{bX}$

$Y=22,649+0,745 X$

Dari permasalahan di atas dapat diartikan bahwa jika besarnya variabel X (multimedia) meningkat 1, maka variabel Y (minat belajar) akan meningkat sebesar: 0,745 . Jika biaya variabel $X$ (multimedia) bernilai nol, maka variabel Y (minat belajar) akan bernilai 22,649, maka dalam penelitian ini adalah $\mathrm{X}=0$ maka harga $Y$ sebesar 22.649.

\section{c) Analisis Koefisien korelasi}

Setelah Menghitung nilai a (konstantan) dan nilai b (koefisien), selanjutnya menghitung anlisis koefisien korelasi dengan rumus:

$$
\begin{aligned}
& r_{x y}=\frac{N \sum X Y-\left(\sum X\right)\left(\sum Y\right)}{\sqrt{\left\{N \sum X^{2}-\left(\sum X\right)^{2}\right\}\left\{N \sum Y^{2}-\left(\sum Y\right)^{2}\right\}}} \\
& r x y=\sqrt{\frac{33.236315-(2766)-(2809)}{\{(33(233008)-(2766) 2\}-\{(33.241077-(2809) 2\}}} \\
& \mathrm{rxy}=\sqrt{\{(7,798,395)-(7,769,694)} \\
& \mathrm{r}_{\mathrm{xy}}=\sqrt{(38,508)-(6,264)-(7,650,756)\}-\{(7,955,541)-(7,890,481)\}} \\
& \mathrm{r}_{\mathrm{xy}}=\sqrt{265552} \\
& \mathrm{r}_{\mathrm{xy}}=\underline{28701} \\
& 162,948 \\
& \mathrm{r}_{\mathrm{xy}}=0,176
\end{aligned}
$$

Harga $r$ tabel untuk taraf kesalahan 5\% dengan $n=33$ diperoleh $r$ tabel $=1,684$ dan karena harga $r_{\text {hitung }}$ lebih kecil $r_{\text {tabel }}$ untuk taraf kesalahan $5 \%(0,176<1,684)$, maka dapat disimpulkan terdapat hubungan yang negatif sebesar 0.176 .

\section{d) Analisis Koefisien Determinasi}

Untuk mengetahui besarnya pengaruh variabel X tehadap variabel Y, maka digunakan koefisien determinasi dengan rumus: 


$$
\begin{aligned}
& D=r^{2} \times 100 \% \\
& D=-0,176^{2}, 100 \% \\
& D=0,303976 \times 100 \% \\
& D=0,030976 \%
\end{aligned}
$$

\section{e) Pengujian hipotesis penelitian ( Uji T)}

Untuk membuktikan hipotesis $\left(\mathrm{H}_{\mathrm{a}}\right)$, korelasi $\mathrm{r}_{\mathrm{xy}}$ sebesar $-1,081$ dan untuk mengetahui signifikan kuat tidaknya pengaruh antara dua variabel dengan menggunakan rumus uji t-test sebagai berikut: (Sugiyono, 2014: 190).

$$
\begin{aligned}
t & =\frac{r \sqrt{n-2}}{\sqrt{1-r^{2}}} \\
t & =\frac{0,176 \sqrt{33-2}}{\sqrt{1-0,176^{2}}} \\
t & =\frac{0,176 \sqrt{31}}{\sqrt{1-0,030976}} \\
t & =\frac{(0,176)(5,568)}{\sqrt{0,969024}} \\
t & =\frac{0,979968}{0,984} \\
& =0,996
\end{aligned}
$$

Dari hasil perhitungan di atas menunjukan bahwa $t_{\text {hitung }} 0,996$ lebih kecil dari $t_{\text {tabel }} 1,684(0,996$ $<1,684)$ pada derajat kebebasan (dk) dari 33dengan taraf nyata $5 \%$, berarti hipotesis $\left(\mathrm{H}_{\mathrm{a}}\right)$ ditolak dan hipotesis $\left(\mathrm{H}_{0}\right)$ diterima, Berdasarkan uraian di atas maka hipotesis yang diajukan dalam penelitian ini DITOLAK artinya tidak ada Pengaruh "Pengaruh Penggunaan Multimedia Terhadap Minat Belajar IPS SMK Negeri 2 Dompu tahun pembelajaran 2016/2017".

\section{B. Pembahasan}

a) Multimedia

Multimedia adalah gabungan dari jaringan-jaringan komputer dalam skala besar dan luas dimana masing-masing komputer tersebut dapat saling berkomunikasi satu dengan yang lainnya menggunakan sebuah bahasa jaringan, Media adalah perantara atau pengantar pesan dari pengirim kepenerima pesan (Sadiman dkk. 1996:19), Data hasil akumulasi angket multimedia, variabel (x) yang dihimpun dari 33 orang siswa kelas $X$ TAV$^{1}$ SMK Negeri 2 Dompu yang dijadikan sampel, peneliti membagikan angket yang berisi 20 soal pilihan ganda untuk variael $X$ dengansoal yang sama pada hari/tanggal, Senin 01 mei 2017, dengan skor penilaian A =SELALU (5),B =SERING (4),KADANG-KADANG(3),TIDAK PERNAH (2), sehingga mencapai hasil $\mathbf{X}=\mathbf{2 7 6 6}$, untuk hasil jawaban angket multimedia variabel $(\mathrm{x})$

Berdasarkan hasil analisis dengan menggunakan rumus regresi linier sederhana dalam penelitian ini diketahui nilai $\mathbf{t}_{\text {hitung }}$ sebesar 0 ,996jauh lebih kecil dari nilai $\mathbf{t}_{\text {tabel }}$ sebesar 1,684 dengan taraf nyata $5 \%$, maka menunjukan tidak adanya pengaruh yang signifikan.Hal ini dikarenakan apabila nilai $\left(\mathbf{t}_{\text {hitung }}\right)$ lebih besar dari nilai $\left(\mathbf{t}_{\text {tabel }}\right)$ dengan taraf nyata 5\% maka akan memberikan pengaruh atau menunjukan adanya hubungan atau pengaruh antara kedua variable, Dengan tidak adanya Pengaruh Penggunaan Multimedia Terhadap Minat Belajar IPS didalam penelitian ini memberikan indikasi bahwa penggunaan multimedia tidakdapat menentukan Minat Belajar Siswa.Multimedia adalah gabungan dari jaringan-jaringan komputer dalam skala besar dan luas dimana masingmasing komputer tersebut dapat saling berkomunikasi satu dengan yang lainnya menggunakan sebuah bahasa jaringan, Gerlach dan Ely (dalam Arsyad, 2007:32) mengatakan bahwa media, apabila dipahami secara garis besar adalah manusia, materi, atau kejadian yang membangun kondisi yang membuat siswa mampu memperoleh pengetahuan, keterampilan dan sikap. 


\section{b) Minat Belajar}

Minat belajar merupakan sifat yang relatif menetap pada diri seseorang, minat besar sekali pengaruhnya terhadap kegiatan seseorang sebab dengan minat ia akan melakukan sesuatu yang diminatinya. Minat adalah "kecenderungan jiwa yang tetap ke jurusan sesuatu hal yang berharga bagi orang. Zakiah Daradjat (1995:133), Data hasil akumulasi angket Minat belajar, variabel (Y) yang dihimpun dari 33 orang siswa kelas X TAV ${ }^{1}$ SMK Negeri 2 Dompu yang dijadikan sampel, peneliti membagikan angket yang berisi 20 soal pilihan ganda untuk variael $Y$ dengansoal yang sama pada hari/tanggal, Senin 01 mei 2017, dengan skor penilaian A =SELALU (5),B =SERING (4),KADANG-KADANG(3),TIDAK PERNAH (2), sehingga mencapai hasil $\mathbf{Y}=\mathbf{2 8 0 9}$ untuk hasil jawaban angket Minat belajar variabel (Y).

\section{c) Pengaruh penggunaan multimedia terhadap minat belajar}

Pada uraian sebelumnya telah cukup banyak menyinggung hakikat mengajar guru dan belajar siswa, jelasnya bagaimana pengaruh buruk mengajar dengan menggunakan alat peraga serta bagaimana siswa meresponnya sebagai upaya mengoptimalkan belajar, dalam hubungannya dengan harapan diatas, para ahli psikologi belajar telah merumuskan beberapa prinsip mengajar dan prinsi belajar, sebagaimana dikemukakan oleh (Hamalik, 1994) menyatakan bahwa pemakaian media dapat meningkatkan keinginan minat yang baru dan motivasi yang tinggi serta membawa pengaruh-pengaruh psikologis pada diri peserta didik, Bertolak dari uji hipotesis, dengan menggunakan rumus regresi linier sederhana dengan uji-t, menenunjukan bahwa dalam penelitian ini diketahui persamaan $\mathrm{Y}=22,649+0,745 \mathrm{X}$, nilai $\mathrm{r}_{\text {hitung }}$ yang diperoleh dalam penyelidikan adalah $=0,996$

Sedangkan nilai $r_{\text {tabel }}$ dengan taraf signifikasi 5\% adalah 1,684 dan koefisien determinasi sebesar $0,030976 \%$ Sedangkan $t_{\text {hitung sebesar } 0,996 \text { dan }} t_{\text {tabel }}$ sebesar 1,684,Maka menunjukan tidak adanya pengaruh yang signifikan. Hal ini dikarenakan apabila nilai $\left(\mathrm{r}_{\text {hitung }}\right)$ lebih besar dari nilai $\left(\mathrm{r}_{\text {tabel }}\right)$

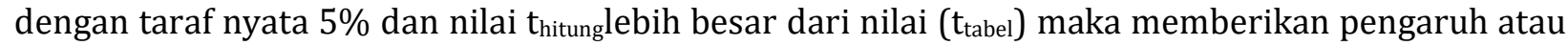
menunjukan adanya hubungan atau pengaruh antara kedua variable, Berdasarkan hipotesis yang diajukan dalam penelitian ini, dapat dikemukakan bahwa hipotesisi nol $\left(\mathrm{H}_{0}\right)$ yang telah dirumuskan diterima dan hipotesisi alternatif $\left(\mathrm{H}_{\mathrm{a}}\right)$ ditolak artinya tidakada Pengaruh Penggunaan Multimedia Terhadap Minat Belajar IPS Siswa SMK Negeri 2 Dompu, Hipotesis merupakan pernyataan yang masih harus diuji kebenarannya secara empirik (Iskandar, 2008 : 56 dalam Musfiqon, 2012: 46). Sedangkan Ahli lain menyebutkan bahwa "Hipotesis adalah suatu jawaban yang bersifat sementara terhadap permasalahan penelitian, sampai terbukti melalui data yang terkumpul" (Suharsimi, 2010:110).

\section{SIMPULAN DAN SARAN}

\section{A. Simpulan}

Berdasarkan penelitian yang telah dilakukan, dapat disimpulkan bahwa $t_{\text {hitung }} 0,996$ lebih kecil dari $t_{\text {tabel }} 1,684(0,996<1,684)$ pada derajat kebebasan $(\mathrm{dk})$ dari 33dengan taraf nyata $5 \%$, berarti hipotesis $\left(\mathrm{H}_{\mathrm{a}}\right)$ ditolak dan hipotesis $\left(\mathrm{H}_{0}\right)$ diterima, Berdasarkan uraian di atas maka hipotesis yang diajukan dalam penelitian ini DITOLAK artinya tidak ada Pengaruh "Pengaruh Penggunaan Multimedia Terhadap Minat Belajar IPS SMK Negeri 2 Dompu tahun pembelajaran 2016/2017".

\section{B. SARAN}

Berdasarkan hasil penelitian ini disarankan beberapa hal diantaranya: 1) dalam proses pembelajaran agar dapat menggunakan multimedia dapat memberikan pengalaman belajar yang lebih kongkrit dan langsung pada siswa. 2) Diharapkan kepada Bapak/Ibu Guru agar dapat berfikir kreatif dalam menentukan dan menggunakan media pendidikan sebagai sarana pendukung proses belajar mengajar guna pencapaian tujuan sesuai dengan yang diharapkan, 3) Kepala Sekolah diharapkan dapat mendorong dan memotivasi guru untuk selalu menggunakan media pembelajaran serta selalu melakukan pendekatan terhadap siswa dan mampu mengarahkan siswa dalam mengembangkan potensi yang ada dalam dirinya.

\section{DAFTAR RUJUKAN}

Ahmad. 1997. Media Intruksional Edukatif. Jakarta: PT. Rineka Cipta. 
Arikunto, Suharsimi. 1998. Prosedur Penelitian Suatu Pendekatan Praktek. Jakarta: PT. Rineka Cipta.

Arsyad. 1997. Media Pengajaran. Jakarta : PT. Grafindo Persada.

Bafadal.1992. Supervisi Pengajaran, Teori dan Aplikasinya dalam Pembinaan Profesionalisme Guru. Jakarta : PT. Bumi Aksara.

Enung Nurhasanah. (2021). Pengembangan Multimedia Pembelajaran Sejarah Perkembangan Islam Berbasis Macromedia Flash untuk Meningkatkan Hasil Belajar Mahasiswa. Ainara Journal (Jurnal Penelitian Dan PKM Bidang Ilmu Pendidikan),2(3), 148-153. Retrieved from http://journal.ainarapress.org/index.php/ainj/article/view/69

Hamalik. 1994. Media Pendidikan. Alumni Bandung

Purwanto. 1984. Administrasi Pendidikan. Jakarta: PT. Rajawali.

Riyanto. 2001. Metologi Penelitian Pendidikan. Surabaya : SIC.

Sadiman,dkk. 1996. Media Pendidikan. Jakarta: CV. Rineka Cipta.

Sanjaya. 2006. Strategi Pembelajaran Berorientasi Standar Proses Pendidikan. Jakarta: Kencana Prasada Media Group.

Soeharto, dkk. 2003. Teknologi Pembelajaran. Surabaya : Surabaya Intellectual Club.

Soemanto. 1998. Psikologi Pendidikan. Jakarta : CV. Rineka Cipta.

Sugiyono, 2005.Statistik Untuk Penelitian.Bandung : CV. Alpabeta.

Sugiyono. 2006. Metode Penelitian Pendidikan Pendekatan Kuantitatif, Kualitatif, dan R\&D. Bandung : Alfabeta

Syaiful, dkk. 2002. Strategi Belajar Mengajar. Jakarta: CV. Rineka Cipta 